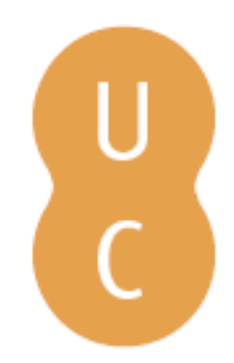

\title{
nommalina
}

\section{Rotas da Natureza nos 10 Anos: da Red de intercâmbios para la historia y la epistemologia de las ciências químicas y biológicas (RIHECQB)}

Autor(es): Janeira, Ana Luísa

Publicado por: Imprensa da Universidade de Coimbra

URL

persistente: URI:http://hdl.handle.net/10316.2/32446

DOI: $\quad$ DOI:http://dx.doi.org/10.14195/978-989-26-0469-5_38

Accessed : $\quad$ 26-Apr-2023 12:00:52

A navegação consulta e descarregamento dos títulos inseridos nas Bibliotecas Digitais UC Digitalis, UC Pombalina e UC Impactum, pressupõem a aceitação plena e sem reservas dos Termos e Condições de Uso destas Bibliotecas Digitais, disponíveis em https://digitalis.uc.pt/pt-pt/termos.

Conforme exposto nos referidos Termos e Condições de Uso, o descarregamento de títulos de acesso restrito requer uma licença válida de autorização devendo o utilizador aceder ao(s) documento(s) a partir de um endereço de IP da instituição detentora da supramencionada licença.

Ao utilizador é apenas permitido o descarregamento para uso pessoal, pelo que o emprego do(s) título(s) descarregado(s) para outro fim, designadamente comercial, carece de autorização do respetivo autor ou editor da obra.

Na medida em que todas as obras da UC Digitalis se encontram protegidas pelo Código do Direito de Autor e Direitos Conexos e demais legislação aplicável, toda a cópia, parcial ou total, deste documento, nos casos em que é legalmente admitida, deverá conter ou fazer-se acompanhar por este aviso.

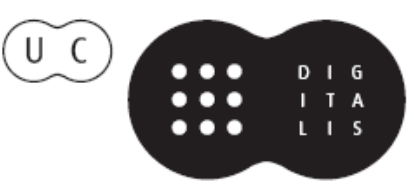


Ana Leunar Pereira João Rui Pita

[ Coordenaçä̃ ]
Rotas da Natureza

Cientistas

Viagens

Expedifgũes

Instituip̧ües

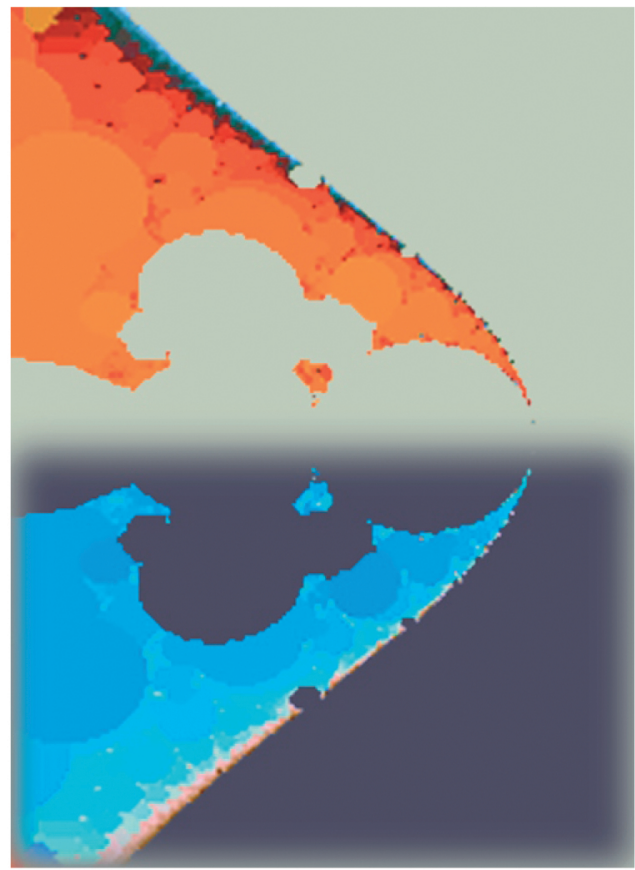




\section{Coordenaçáo Científica da Colecção Ciências e Culturas}

João Rui Pita e Ana Leonor Pereira

Os originais enviados são sujeitos a apreciação científica por referees

\section{Coordenação Editorial}

Maria João Padez Ferreira de Castro

\section{Edição}

Imprensa da Universidade de Coimbra

Email:impresauc@ci.uc.pt

URL: http://www.imp.uc.pt • Normas de publicação de colecçôes

\section{Design}

António Barros

Pré-Impressáo

António Resende

Imprensa da Universidade de Coimbra

\section{Capa}

António Barros, com imagem de E. M. de Melo e Castro, 2003 [Fractal original gerado no Fractint com tratamento no Photoshop 7.0]; Cortesia: António Barros

Impressão e Acabamento

SerSilito • Maia

\section{ISBN}

978-989-8074-12-6

\section{Depósito Legal}

Obra publicada com a colaboraçáo de:
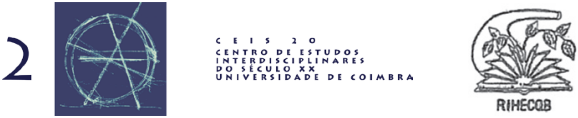

Obra publicada com o apoio de:

FCT Fundação para a Ciência e a Tecnologia

MINISTÉRIO DA CIÊNCIA, TECNOLOGIA E ENSINO SUPERTOR Portug

Programa Operacional Ciência, Tecnologia, Inovação do Quadro Comunitário de Apoio III
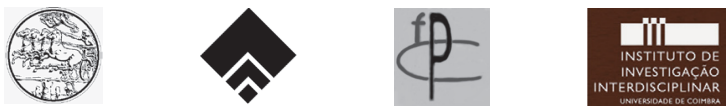

\section{Baxter}

(c) 2006, Imprensa da Universidade de Coimbra 
João Rui Pita

Ana Leonar Pereira

(Courdenação)

Rotas da Natureza

Cientistas

Viagens

Expediçũes

Instituiç̃̃es

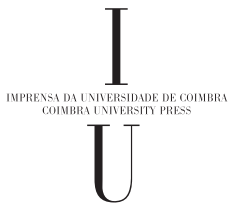

- colmbra 2006 
(Página deixada propositadamente em branco) 


\author{
Ana Luísa Janeira \\ Coordenadora da Red de Intercambios para la Historia y la Epistemologia de las Ciencias \\ Químicas y Biológicas (RIHECQB) em Portugal
}

\title{
Rotas da Natureza nos 10 AnOs. DA Red \\ DE INTERCÂMBIOS PARA LA HISTORIA Y LA EPISTEMOLOGIA DE LAS CIÊNCIAS QUÍMICAS Y BIOLÓGICAS (RIHECQB)
}

Rota, se olharmos para o céu a palavra lembra planetas e cometas. Mas também caminho, caminho por terra, marítimo ou pelo ar. Rumo. O rumo das coisas, das gentes, das ideias.

Num processo com várias rotas anteriores, realcemos como, neste particular, os descobrimentos ibéricos reinventaram as conquistas, ao mesmo tempo que aproximaram os mundos. Trouxeram a novidade, o exotismo, a matéria-prima, o conhecimento endógeno, os indígenas. Mestiçaram flora, fauna, pessoas. Misturaram e relançaram o formato da miscigenação como base do desenvolvimento moderno. Somos o produto desse processo.

A Ciência, a Tecnologia, e as suas Histórias, reflectem necessariamente estes movimentos: expedições científicas, colecções, museus. E também os (in)fluxos entre conquistadores e conquistados, amos e escravos, Oriente e Ocidente, Velho e Novo Mundo, metrópoles e colónias, Norte e Sul.

Que rotas continuaram ou desapareceram desde há muito, como continuam ainda agora, ou estão a emergir, marcando o quotidiano de muitos e a comunidade científica em geral?

Rotas são passagens. De ponto para ponto. Os intercâmbios apoiam-se nelas. Quem passa nas rotas são seres, artefactos, conhecimentos.

Como se foi transformando e se transforma ainda o mundo, na apregoada globalização?

O desafio destas Comemorações reside em determinar os ingredientes e a fórmula da Mistura que lhes subjaz: para cada lugar e num tempo determinado, que elementos novos introduzidos, que descontinuidades provocadas, que salto em frente no processo, que agentes de mudança?»

Escrito por Isabel Cruz ${ }^{1}$, este texto sintetiza de uma forma basilar o espírito que norteou a forma como interiorizámos e exteriorizámos o desejo que as demais coor-

\footnotetext{
${ }^{1}$ Membro da direcção do CICTSUl e principal dinamizadora do Colóquio Internacional I.
} 
denadoras exprimiam, quando voltavam a escolher Portugal para a reunião celebrativa dos dez anos.

Assim a Red de Intercambios para la Historia y la Epistemologia de las Ciencias Químicas e Biológicas - RIHECQB - foi criada, em 1992, pelas professoras doutoras Patrícia Aceves Pastrana, coordenadora (UAM-Xochimilco, México), Ana Luísa Janeira (Universidade de Lisboa, Portugal), Ana Maria Alfonso-Goldfarb (PUC - São Paulo, Brasil) e Celina Lértora Mendonza (CONICET-Argentina), vivamente empenhadas em incrementar o intercâmbio entre investigadores em História da Ciência, actuando em diversas áreas e oriundos de diferentes regiōes, nomeadamente a América Latina e a Península Ibérica.

$\mathrm{Na}$ verdade, tendo nascido à volta de uma refeição muito animada, com variados e suculentos pratos de bacalhau, num conceituado restaurante de São Cristóvão no Rio de Janeiro, logo ali se decidiu que a primeira reunião seria em Lisboa, um ano depois.

Desde então, a RIHECQB vem realizando, anualmente, entre um a dois encontros, em países diferentes (México, Brasil, Argentina, Portugal, Espanha).

O seu produto mais visível encontra-se materializado em "Estudios de história social de las ciencias químicas y biológicas», colecção organizada por Patrícia Aceves Pastrana, com já sete números publicados, bem como noutras publicações, incluindo trabalhos do grupo de professores que a compõem.

Entretanto, insista-se nesta especificidade, ao longo deste período, medraram várias actividades, nomeadamente através de uma presença bem integrada entre Colóquios organizados inteiramente pela Red, ou Seminários integrados em grandes Congressos Internacionais. Com efeito, os membros têm-se mostrado capazes de desenvolver uma dinâmica, em prol de uma participação sintonizada e de conjunto em congressos internacionais da área, apresentando pesquisas subordinadas a um tema comum.

Dada a virtualidade e a concretização deste processo geral de intercâmbio, que faz juz ao segundo termo do seu nome, a Red tem criado uma rede de afectos que vêm sendo renovados pela capacidade de marcar um ritmo de persistências e de reencontros.

Sendo esta a energia que preside às reuniões gerais, foi nossa intenção que o encontro de 2003 propiciasse, por si mesmo e na estutura, a concretização de uma percurso enriquecido por diferenças e misturas, em vários sentidos.

Assim, o Colóquio comemorativo dos 10 anos da Red de Intercambios para la Historia y la Epistemologia de las Ciencias Químicas y Biológicas (RIHECQB) desdobrou-se em dois momentos sequenciais com complementaridade intrínseca, mas autónomos:

- Colóquio Internacional I. Rotas da Natureza: Senso Comum, Vivências e Conhecimento Científico, Lisboa, 27 a 29 de Junho de 2003, Organização do Centro Interdisciplinar de Ciência, Tecnologia e Sociedade da Universidade de Lisboa (CICT-SUl) e do Instituto de São Tomás (ISTA)

- Colóquio Internacional II. Rotas da Natureza: Cientistas, Viagens, Expedições e Instituições, Coimbra, 30 de Junho a 2 de Julho de 2003 Organização do Centro de Estudos Interdisciplinares do Século 20 (CEIS20)

Anote-se ainda como o espírito de intercâmbio presidiu ao convívio interdisciplinar que norteou as instâncias organizativas de ambos os eventos. 
Deste modo, presidiu-lhes a Comissão Científica da Red com Ana Goldfarb (Química, Brasil), Ana Luísa Janeira (Filosofia, Portugal), Celina Lertora (Direito, Argentina), Javier Puerto (Farmácia, Espanha), Márcia Ferraz (Química, Brasil), Patrice Bret (História, França) Patricia Aceves (Química, México); e a Comissão Executiva com Alexandra Escudeiro (Biologia, U. Lisboa) A. Amorim da Costa (Química, U. Coimbra), Ana Leonor Pereira (História, U. Coimbra), Isabel Cruz (Química, U. Autonoma Madrid), João Rui Pita (Farmácia, U. Coimbra), José Augusto Mourão (Semiótica, U.N. Lisboa), a quem muito agradeço a colaboração empenhada e frutuosa. 


\section{Colecçãa \\ 2 Ciências e Culturas Caimbra 2006}

